\title{
Predicting the Use of Twitter in Developing Countries: Integrating Innovation Attributes, Uses and Gratifications, and Trust Approaches
}

\author{
Mohammad A. Alajmi, Awadh H. Alharbi, and Husain F. Ghuloum \\ Public Authority for Applied Education and Training, Kuwait
}

\author{
moh ku@hotmail.com; Ah.alharbi@paaet.edu.kw; \\ hf.ghuloum@paaet.edu.kw
}

\begin{abstract}
Based on the diffusion of innovation (DOI) theory (Rogers, 2003), the uses and gratifications (U\&G) theory (Blumler \& Katz, 1974), and trust theory (Mayer, Davis, \& Schoorman, 1995), this study investigated the factors that influence the use of Twitter among the Kuwaiti community. The study surveyed Twitter users in Kuwait. A structured online questionnaire was used to collect data, and 463 respondents who provided complete answers participated. Multiple regression analysis was used to examine the effect of three theoretical perspectives on Twitter usage. The result of the analysis showed that Twitter usage is better explained by DOI constructs than by U\&G constructs. The findings indicated that the perceived relative advantage from DOI, and the need for information, need to pass time, and need for interpersonal utility from the U\&G approach, have a direct positive significant effect on the use of Twitter. None of the trust theory constructs was found to be significant in predicting the general use of Twitter. The study results help Twitter providers and users in individual or organizational contexts to understand what factors generally affect the usage of the Twitter service.
\end{abstract}

Keywords: social media, microblogging, Kuwait, diffusion of innovation, motivations, trust objects, communication technology

\section{Introduction}

Social networking sites (SNSs) play an increasingly important role as efficient communication tools for social and participatory activities in which users co-create, collaborate, share and modify content (Kaplan \& Haenlein, 2010). New communication tools have become a major issue within society and have captured the attention of researchers around the world as a significant research topic (Park \& Kim, 2013). SNSs have

Material published as part of this publication, either on-line or in print, is copyrighted by the Informing Science Institute. Permission to make digital or paper copy of part or all of these works for personal or classroom use is granted without fee provided that the copies are not made or distributed for profit or commercial advantage AND that copies 1) bear this notice in full and 2) give the full citation on the first page. It is permissible to abstract these works so long as credit is given. To copy in all other cases or to republish or to post on a server or to redistribute to lists requires specific permission and payment of a fee. Contact Publisher@InformingScience.org to request redistribution permission.

led to the publication of a number of studies in different contexts such as the stock market, parliamentary and presidential elections, emergency events, crises, health, education, business, and so on (Evangelopoulos, Magro, \& Sidorova, 2012; Lacka \& Chong, 2015; Liu, Liu, \& Li, 2012; Pere-Latre, Portilla, \& Blanco, 2010; Prybutok, 2013). Owing to the differences in SNSs' pur- 
poses, users, and interfaces, the characteristics and the motivations for the use of individual SNSs need to be investigated, and additional significant factors in different cultures addressed.

In line with the philosophy of informing science, Cohen (2009) provides a way of analyzing the role of SNSs as sufficient informing channels for users to create and share content. SNS users interchange the roles of informers (sources) and clients (recipients), whereas SNS platforms serve as the medium where messages can be created, collaborated, and modified by users. Hardin, Ryan, and Prybutok (2012) extended the framework of Cohen's work and suggested that an informing system had three dimensions: "the informing environment, the delivery system, and the task completion system" (p. 207). They identified SNSs as informing channels or delivery systems for mass and interpersonal communication. Extending the effectiveness of informing channels, SNS platforms, in particular, require transdisciplinary research, in developing countries, to understand the usage and acceptance of informing channels.

As a form of SNS, Twitter, which was launched to the public in October 2006, is one of the newest developments, and is currently the most widely used microblogging platform. Twitter, which has elements of both mass and interpersonal communication, enables users to send, distribute, and read short posts of 140 characters in length (Java, Song, Finin, \& Tseng, 2007). The service requires users to create a username and a brief online profile to benefit from common elements much like those of email, instant messaging, RSS, texting, blogging, and so forth. Twitter users can send and receive messages - "tweets" - which are in the public domain by default unless a user chooses to keep updates private. In July 2014, The Statistic Brain (2014) reported that the total number of active registered Twitter users exceeded 645 million, with 58 million average tweets per day being tweeted.

Twitter has become deeply embedded in modern society, not only in developed countries but also in developing countries. The Arab social media report showed that the Arab region is a part of the world where SNSs are flourishing (Salem \& Mourtada, 2012), although researchers have pointed out that other information technologies have suffered total or partial failure in developing countries. In contrast to the uptake of other information technologies, Arab countries have registered a high level of Twitter usage. As of July 2012, the top two SNSs in the Arab region were Facebook and Twitter. According to the Arab social media report, the estimated number of active Twitter users in the Arab region at the end of June 2012 was 2,099,706, tweeting 172 million tweets in March 2012; 88\% of the tweets were generated by five Arab countries: Egypt, Saudi Arabia, Kuwait, United Arab Emirates, and Lebanon (2012). Furthermore, a report from 2013 indicated that the highest number of Twitter users in the Arab region came from Kuwait (7.6\%), based on the penetration rate (Dubai School of Government, 2013).

While a significant number of information technologies fail or partially fail in developing countries, others have registered high levels of usage. This information lays the groundwork for understanding the reason behind the recent popularity of Twitter among so many internet users. Despite the widespread flourishing and rapid spread of Twitter in the business world in developing countries, the research on Twitter is still at the exploratory stage, in particular in the Arab region. The population of Kuwait was selected for this study for a number of reasons. First, as previously mentioned, Kuwait ranks highly in terms of Twitter penetration in the Arab world and, as such, it is important to explore the pattern and drivers of this growth. Second, Twitter usage in Kuwait is not clearly motivated by a particular issue or movement that may affect and introduce biases to the purpose of the current study, unlike the situation in other Arabic countries where revolutions have taken place (Abdelhay, 2012; Shirazi, 2013). Lastly, the cultural and traditional characteristics as well as the general perspective of Kuwait support the right to freedom of speech, critique and expression, and these are inherent and vital aspects of Twitter (Ladhani, 2012; Shirazi, 2013). Therefore, this study was undertaken in order to better understand the impact of multiple dimensions of factors on Twitter usage through the community of Kuwait. More specifically, this study 
investigated the influence of user-related characteristics, including motivations and trust, and technology-related characteristics, on Twitter usage in Kuwait.

\section{Background}

\section{Research on Twitter}

As internet technology evolves, there is a strong thrust to provide powerful new technologies, namely SNSs, whether for strengthening social networks or for diffusing immediate information. Twitter, an SNS, "is a real-time information network powered by people all around world...Twitter asks 'what's happening' and makes the answer spread across the global to millions, immediately" (www.Twitter.com/about). In other words, Twitter is a web-based microblogging service that enables users to send and receive short messages, named tweets, to and from other users, named followers. SNSs share the advantages of ease of use, immediacy, and cost-effectiveness (Peterson, 2012). Twitter stimulates users to engage in timely and up-to-date activities with families, friends, and co-workers, sharing information, news, and opinions (Honeycutt \& Herring, 2009). Therefore, the Twitter platform serves as an infrastructure in which, on the one hand, individual informers deliver messages to individual clients and, on the other hand, because of the large public nature of the information exchanged, Twitter itself becomes the informer, providing aggregate information to clients (Evangelopoulos et al., 2012).

Over the last few years, several streams of research have investigated the acceptance and use of Twitter by internet users. Barnes and Bohringer (2011) and Sreenivasan, Lee, and Goh (2012) classified microblogging and Twitter research into two major categories: understanding the characteristics of microblogging and user behavior; and investigating microblogging applications in different settings. The first research stream focuses on presenting statistical description and modeling user behavior. Java et al. (2007) characterized user types and different usage of Twitter. Similarly, Krishnamurthy, Gill, and Arlitt (2008) identified user types and statistical status, but with respect to geographical growth patterns and number of users. Research has also focused on enhancing the social presence and maintaining connectedness within the collaborative characteristics of microblogging communication (Honeycutt \& Herring, 2009; Zhao \& Rosson, 2009). Further statistical studies on Twitter have focused on understanding the top trending topics in microblogging communication (Kwak, Lee, Park, \& Moon, 2010; Naaman, Becker, \& Gravano, 2011). Aladwani (2015) introduced a framework dividing Twitter use into three major components: facilitators, characteristics, and impacts. The author measured the three components through multi-group settings: individuals, business representatives, and government representatives.

The second stream of research provides an overview of the possibility of using microblogging services in special settings, such as enterprise information management, marketing, political elections, emergency communication, and e-learning (Hargittai \& Litt, 2011; Liu et al., 2012; Ross, Terras, Warwick, \& Welsh, 2011). For example, as extensions to their model based on the unified theory of acceptance and use of technology (UTAUT), Gunther, Krasnova, Riehle, and Schonberg (2009) identified relevant factors affecting usage in enterprises, including "privacy concerns" and "collaborative norms." In the special case of marketing, Witkemper, Lim, and Waldburger (2012) identified the motivations and constraints that influence sport Twitter consumption (STC). The findings from their study indicated that the motivations were positively and significantly related, while the constraints were negatively and significantly related, to users' STC with regard to following athletes. Further, SNSs, including Twitter, have contributed value as educational tools because students and teachers can use them for communication and collaboration, as well as for discovering and sharing resources and knowledge (Lee \& McLoughlin, 2010; Stanciu, Mihai, \& Aleca, 2012). Past studies have assessed the use of Twitter in emergency communica- 
tion by comparing it with mainstream information channels (Li \& Rao, 2010; Mills, Chen, Lee, \& Rao, 2009).

Twitter is not the first information technology to have emerged in developing countries, but the research indicates that, statistically, the service continues to be one of the most popular information technologies in the Arab region. The popularity of Twitter in the societies of the region calls not only for official reports presenting statistical descriptions, but also for an in-depth understanding of the factors affecting Twitter adoption in these societies (Al-Jabri, Sohail, \& Ndubisi, 2015). In addition, extending such an understanding is likely to be rewarded and encouraged by research that crosses disciplinary boundaries (Cohen, 2009). Therefore, a successful information technology such as Twitter needs to be theoretically explored in detail in terms of user-related and technology-related characteristics, given the limited adoption of other information technologies in the Arab region. Based on Blumler and Katz's (1974) uses and gratifications (U\&G) theory, Mayer, Davis, and Schoorman's (1995) trust theory, and Rogers' (1962, reprinted 2003) diffusion of innovation (DOI) theory, this study explored how users accept and adopt Twitter. In particular, we focused on the user-related characteristics using U\&G and trust theory, and technology-related characteristics using DOI.

\section{Theoretical Background and Research Model}

\section{Diffusion of Innovation}

DOI is mainly concerned with understanding the process by which innovations propagate in a social system over time. Rogers (2003) defined diffusion as "the process by which an innovation is communicated through certain channels over time among the members of a social system" ( $p$. 5), while an innovation is "an idea, practice, or object that is perceived as new by an individual or another unit of adoption" (p. 12). DOI and its empirical literature research have offered insights into several characteristics of technology that affect an individual's decision whether to adopt or reject the technology. The adoption decision has been measured in previous DOI research based on several constructs, including the personal innovativeness of the adopter, the popularity of an innovation, and the characteristics of an innovation.

RQ1: How much do personal innovativeness, perceived popularity, and perceived characteristics of the innovation affect the use of Twitter in the community of Kuwait?

\section{Personal innovativeness}

The notion of personal innovativeness represents a significant development in information technology innovation research. Rogers (2003) defined innovativeness as "the degree to which an individual or other unit of adoption is relatively earlier in adopting an innovation than other members of a social system" (p. 22). According to Midgley and Dowling (1978), innovativeness refers to "the degree to which an individual is receptive to new ideas and makes innovation decisions independently of the communicated experience of others" (p. 236). Personal innovativeness may be used as a moderating factor affecting the relationship between perceptions of an innovation and intention to use the innovation, or as preliminary predictor of the adoption of an innovation (Agarwal \& Prasad, 1998; Rogers, 2003). Scholars have employed the construct of personal innovativeness in DOI-related studies to find out how significant innovativeness is for the adoption of new media or technology (Kang, 2002; Lin, 1998; Zhu \& He, 2002). These studies revealed different findings on the effect of personal innovativeness on adoption. More specifically, Zhu and He (2002) found that personal innovativeness was not significant in predicting the adoption of the internet in China, while Lin's (1998) findings showed a positive significance for the influence of innovativeness in the adoption of the personal computer. In our study, we set personal innovativeness as a preliminary factor. Hence, we hypothesized that: 
H1: The rate of Twitter adoption is significantly predicted by perceived personal innovativeness.

\section{Perceived popularity of an innovation}

DOI has emphasized the importance of the social system and mass media in transferring information about an innovation to individuals. Rogers (2003) discussed the effect of the social system - such as family members, friends, and co-workers - and mass media on the use of innovations, and referred to this as perceived popularity. Diffusion scholars have used social atmosphere, social pressure, cultural fashion, and other concepts to identify the role of social systems and mass media in the DOI process. Due to the culture beliefs and norms, people in the Arab region tend to resist using social media and prefer to maintain offline social communication (Straub, Loch, \& Hill, 2001). However, empirical research on this subject found that Arabs were willing to use SNS while preserving their social norms (Loch, Straub, \& Kamel, 2003). Generally, the notion of perceived popularity has been accepted as an extremely relevant construct for the individual's innovation adoption (Fulk, 1993; Schmitz \& Fulk, 1991). Therefore, we assumed that the effect of social systems and mass media would be a significant predictor for Twitter usage. Accordingly, we hypothesized the following statement:

$\mathrm{H} 2$ : The rate of Twitter adoption is significantly predicted by its perceived popularity.

\section{Perceived characteristics of an innovation}

Diffusion researchers have found that innovation attributes are core constructs affecting innovation usage (Moore \& Benbasat, 1991; Rogers, 2003; Tornatzky \& Klien, 1982). Rogers (2003) posited a set of innovation attributes that explain what may affect the rate of adoption, namely: relative advantage, compatibility, complexity, trialability, and observability. Diffusion and adoption studies have concluded that the way in which targeted adopters perceive the attributes of an innovation is critical, and that these perceptions account for $49-87 \%$ of the variance in the rate of innovation adoption (Rogers, 2003).

Relative advantage refers to the degree to which an innovation is considered to be a better alternative than its precursors. Compatibility means the extent to which an innovation is perceived to be consistent with the existing values, needs, and past experience of an adopter. Complexity refers to the degree to which an innovation is difficult to understand or to use. Trialability means the degree to which an innovation may be tried by adopters on a limited basis. Finally, observability refers to the degree to which the results and uses of an innovation are visible and observable to others (Rogers, 2003).

As information systems and communication began to grow and develop, Rogers' five innovation attributes were revised based on the specific case of technology innovation. Revising Rogers' innovation attributes showed that, for instance, observability seemed to be divided into two distinctly different constructs: visibility and result demonstrability. Visibility refers to the degree to which the use of a system is apparent, whereas result demonstrability refers to the degree to which the outcomes of the use of a system are apparent and discernible (Moore \& Benbasat, 1991). Another aspect of the revision of Rogers' five innovation attributes relates to the application of the ease of use construct directly from Davis' Technology Acceptance Model, as a proxy for the construct of complexity. Drawing on Rogers' five innovation attributes and the recent revisions, we contend that the following six attributes are particularly relevant to the adoption of Twitter: relative advantage, compatibility, ease of use, visibility, result demonstrability, and trialability. Thus, we hypothesized the following:

H3: The rate of Twitter usage is significantly predicted by the perceived attributes of Twitter. 


\section{Uses and Gratifications}

Unlike other theories, U\&G is widely applied in a range of media technology research, including on SNSs (Sangwan, 2005). U\&G regards individuals as agents who perform different actions based on the needs that users expect to satisfy through their use. In other words, U\&G focuses on the motives for specific types of usage, and the satisfaction individuals obtain from such use (Stafford, Stafford, \& Schkade, 2004).

Modern society is information-oriented (Rogers, 2003), and prefers to replace traditional massexposure media with an interactive collection of communication media represented by the modern internet (Stafford \& Stafford, 1998). SNSs like Twitter are still in the initial adoption stage of new media usage, and U\&G is a time-honored media-use theory that is helpful for understanding and analyzing a relatively new medium such as Twitter. Compared to other SNSs, Twitter's success is attributed to its communication brevity and interactivity. Comparisons have also shown that Twitter's primary role is in fulfilling information needs rather than social needs (Johnson \& Yang, 2009).

RQ2: How much do personal motivations affect Twitter usage in the community of Kuwait?

\section{Perceived motivations}

From its initial formulation to its current applications, the U\&G perspective has provided insights that offer an understanding of the motives for using electronic media. In its early days, U\&G was used to identify and profile audience motivations for the use of radio and early television media. The approach was later applied to new media, such as cable transmission, video recording, and the telephone, by advertising and marketing researchers (Leung \& Wei, 2000). The internet and its constituent technologies and media, such as personal homepages and email, have been targeted by researchers using the U\&G approach to identify the underlying motivations behind their use (Papacharissi, 2002; Papacharissi \& Rubin, 2000; Stafford et al., 2004).

In the context of social media, the research into $U \& G$ in relation to Twitter has been widely used to measure Twitter users' motivations and associated behavior. For example, researchers have used $U \& G$ in order to better understand the extent to which users expect that various social and psychological needs will be satisfied by the use of Twitter (Agrifoglio, Black, Metallo, \& Ferrara, 2012; Coursaris, Van Osch, Sung, \& Yun, 2013; Holton, Baek, Coddington, \& Yaschur, 2014; Johnson \& Yang, 2009). These studies identified various motivations for general Twitter use. More specifically, Coursaris et al. (2013) identified two categories of motivation for active Twitter users, namely information and relaxation, while three categories were significant for inactive users, namely information, relaxation, and social interaction. Witkemper et al. (2012) examined what motivations and constraints influence Twitter adoption as a medium for following users' favorite athletes. To measure the motivation and constraint factors that influence STC, they identified four motivations - information, entertainment, passing time, and fanship - and four constraints - accessibility, economic, skills, and social. Contextually, the Arab world has embraced SNS, which offers enormous opportunity for gratifying their needs for social interaction, enjoyment, information exchange, and freedom of expression. In a comparative study of three countries - USA, Thailand, and Bahrain - Ribiere, Haddad, and Wiele (2010) examined social and cultural motivations in predicting the usage of SNSs. They found that uncertainty avoidance, maintaining relationships, online privacy, and perceived usefulness were significant in explaining the expressive usage, while long-term orientation and perceived usefulness were significant for the instrumental usage of SNSs. Under some restricted situations, Al-Jabri et al. (2015) investigated the effects of four motivations as well as the moderating effects of gender and user experience on Twitter usage in Saudi Arabia. The findings support the effects of enjoyment, freedom of expression, and social interactions on Twitter usage and the moderating effect of gender and user expe- 
rience between self-presentation and usage. Based on these findings, we hypothesized the following:

H4: The rate of Twitter usage is significantly predicted by the perceived needs.

\section{Trust Theory}

This study also aimed to add another important dimension, namely trust, to the investigation of Twitter adoption. Generally, trust is defined as "the willingness to rely on a specific other, based on confidence that one's trust will lead to positive outcomes" (Chopra \& Wallace, 2003, p. 3). According to the literature, trust is grounded on trustworthiness, which is defined as "the guarantee required by the truster that the trustee will act as it is expected to do without any supervision" (Taddeo, 2010, p. 250). Trustworthiness has explicitly been identified by several characteristics that are responsible for trust (Mayer et al., 1995; McKnight, Choudhury, \& Kacmar, 2002; Rousseau, Sitkin, Burt, \& Camerer, 1998). Although a number of factors have been identified, three characteristics have been widely discussed in the literature and explain a major portion of trustworthiness: competence (trustee's ability to do what is needed by the truster), benevolence (trustee's caring about acting in the best interest of the truster), and integrity (trustee's honesty and commitment-keeping) (McKnight et al., 2002).

Concerns about trust in online environments have greatly increased because so many transactions - social, informational, commercial, and governmental - are accomplished electronically (Tufekci, 2008). Indeed, trust research in online environments underlines the importance of distinguishing between trust as a belief in the advantages of the other party and trust as an intention to assume uncertainty and risk that make one vulnerable to another individual (Chopra \& Wallace, 2003; Mayer et al., 1995). Trust in information systems is the first step in users' participation in trusting relationships of online interaction. For example, studies focusing on e-commerce have found that, directly and indirectly, trust can positively impact online purchasing (Awad \& Ragowsky, 2008, Gefen, Karahanna, \& Straub, 2003; Lin, 2011; McKnight et al., 2002).

Trust is also important for successful online relationships, as well as for modeling behavior in SNSs. In SNSs, a member usually shares, communicates, and interacts with another member by a set of relationships that are managed through a website (Downes, 2005). Given the importance of trust in traditional social networks, it is important to understand how trust and trusting behavior occur in SNSs. On joining an SNS, users begin by creating a profile that reveals personal information then make connections with those they meet through the website through the network of the internet (Dwyer, Hiltz, \& Passerini, 2007). Based on this statement, trust in the context of SNSs possibly consists of three objects: trust in the community of users, trust in SNSs, and trust in the security services and technical solutions of the internet that are embedded in Web 2.0 technologies.

The majority of studies in the SNS literature have limited their focus to the motivations for Twitter use in understanding user behaviors. However, this study aims to extend the understanding of user behavior by also focusing on trust and trusting behavior. Thus, this study attempts to answer the following research question:

RQ3: How much do the objects of trust affect Twitter usage in the community of Kuwait?

Considering the community of users of a particular SNS as objects of trust, a user's belief about specific characteristics of other users (characteristics of communication partners) in the SNS, such as their competence, ability, integrity, and benevolence, will affect the intention to adopt SNSs. In the context of disposition to trust or trust propensity, McKnight et al. (2002) focused on aspects of trustworthiness between a person and others across a broad spectrum of situations and persons. Accordingly, characteristics of communication partners might be perceived differently in 
electronic environments, and the perceived value of these characteristics may be different in SNSs than in real-world interactions (Mayer, 2009). Studies concentrating on SNSs have found that, directly and indirectly, the trust people have toward their community of users on their SNSs can positively impact the adoption of SNSs. The perceived benevolence and competence of one's community of users on an SNS, for example, influence information-sharing and use behaviors (Fang \& Chiu, 2010; Ridings, Gefen, \& Arinze, 2002; Turel \& Gefen, 2013). Based on these findings, the rate of usage of SNSs is influenced by users' trust in their community that is hosted on the SNS.

The SNS can be considered as another object of trust that captures characteristics of an organization (the network provider) or technology (the internet serving as a transmission medium for online activities, or, more specifically, the security services and technical solutions embedded in Web 2.0 technologies). Thus, SNS adoption can be influenced by personal or organizational characteristics that reflect the factors of trustworthiness, such as competence, benevolence, and integrity. Disclosing personal information to an SNS provider is a critical issue in the context of online environments. However, users of SNSs claim to trust that SNS providers will not misuse their information (Krasnova, Spiekermann, Koroleva, \& Hildebrand, 2010). McKnight et al. (2002) argued that, in situations where users choose to reveal personal information to an SNS provider, they will be interested more in its benevolence and integrity than in its competence. Thus, the factors of benevolence and integrity of a service provider are assessed in our trust conceptualization in relation to the use of Twitter.

The adoption of online services can be influenced not only by a service provider but also by technology-related characteristics, such as functionality, reliability, and security (Ratnasingam, 2005). In the context of e-commerce, several researchers have considered technology itself as another object of trust. The focus has been on security services and technical solutions embedded in ecommerce technologies (Corritore, Kracher, \& Wiedenbeck, 2003; Grabner-Krauter \& Faullant, 2008). Like e-commerce, SNS technology itself can be considered as an object of trust because the trust in the technical aspects of SNSs is based on perceived functionality (e.g. reliability, correctness, and security) (Grabner-Krauter, 2009). The structural assurance dimension of institution-based trust is closely related to an individual's perception of the characteristics of technological systems as a specific type of trust (McKnight et al., 2002). These considerations suggest that a high level of web-related structural assurance would influence Twitter adoption. Thus, we hypothesized the following:

H5: The rate of Twitter usage is significantly predicted by the trust in the Twitter provider, trust in other members, and structural assurance.

\section{Methodology}

\section{Sample and Data Collection}

We targeted Kuwaiti users of Twitter, which is the sixth most popular website in Kuwait, according to Alexa.com statistics. Furthermore, Mocanu et al. (2013) identified that Twitter users in Kuwait are ranked first globally in adopting Twitter in terms of the ratio between Twitter users and the total population. Thus, it is crucial to understand what factors influence users in Kuwait to adopt Twitter.

An online questionnaire was conducted for data collection using Survey Monkey, an online tool that enables individuals to establish their own surveys (www.surveymonkey.com). An announcement with a hyperlink to the online questionnaire system was posted to the most popular Twitter accounts in Kuwait. The announcement stated the aim of the study and the qualifications for participating in the questionnaire. Responses were collected from 1 to 30 April 2014. Among 
the 645 questionnaires collected, only 463 were fully usable, because some were incomplete and had to be discarded. Owing to the high number of incomplete surveys, a Chi-test was used to compare the demographic attributes of the incomplete survey and the useful survey on one side, and to compare the early respondents with the late respondents on the other. The results revealed no significant differences, suggesting that there was no substantive response bias. Data were entered into SPSS for further analysis.

\section{Measures}

We developed an online questionnaire with 83 items (4 demographic questions; 3 measuring the level and method of Twitter use; 27 items relating to the characteristics of the Twitter service; 27 focusing on Twitter U\&G; and 14 assessing trust objects).

The first part of the questionnaire collected demographic data about the respondents, including gender, age, education, and occupation.

The second part of the questionnaire used different types of Likert scales, and posed three general questions regarding the means by which the respondents access Twitter, the frequency with which the respondents post tweets, and the frequency with which the respondents read others' postings on Twitter.

The third part was used to measure the characteristics of the Twitter service. This section was created to reflect Rogers' attributes of innovation, including relative advantage, compatibility, complexity, trialability, and observability. One of the most famous and oft-used instruments in information technology innovations is Moore and Benbasat's instrument (1991), which was developed based on Rogers' attributes of innovation. With suitable adaptation in the items for the adoption of Twitter, we applied Moore and Benbasat's instrument for the perceived characteristics, and applied questionnaire items for personal innovativeness from Chang, Lee, \& Kim's (2006) instrument and for perceived popularity from Zhu and He's (2002) instrument. We used four items on a five-point Likert scale ranging from "strongly disagree" (1) to "strongly agree" (5) to measure the perceived characteristics, except perceived popularity, perceived innovativeness, and compatibility, which were measured using three items on the same scale.

The fourth part focused on assessing perceived needs for adopting Twitter, which involved eight constructs (need for entertainment, need to pass time, need for escape, need for relaxation, need for information sharing, need for information seeking, need for interpersonal utility, and need for professional advancement), derived from four aforementioned studies (Coursaris et al. 2013; Holton et al., 2014; Papacharissi \& Rubin, 2000; Witkemper et al. 2012). Some items in this study were adapted to fit the context of the Twitter service. On the same scale used for the characteristics of Twitter, we used four items to measure the need to pass time, need for information sharing, need for professional advancement, and three items for need for entertainment, need for interpersonal utility, need for escape, need for relaxation, and need for information seeking.

The final part of the questionnaire was used to assess the trust objects, and focused on three constructs, namely trust in the Twitter community, trust in the Twitter provider, and trust in the internet. The trust object measures were derived from trust beliefs literature (Gefen et al. 2003; Krasnova et al., 2010; McKnight et al., 2002; Turel \& Gefen, 2013) and adapted to suit the research context. On a five-point Likert scale ranging from "strongly disagree" (1) to "strongly agree" (5), 14 items were used to measure the three constructs (five items for trust in the Twitter community, five items for trust in the Twitter provider, and four items for trust in the internet). 


\section{Data Analysis and Results}

\section{Twitter Usage}

With regard to respondents' gender, $51 \%(n=236)$ were female and $49 \%(n=227)$ were male. In terms of the age distribution, most respondents $(62.9 \%)$ were in the age range $18-24$ years, $6.9 \%$ in the age range $25-34$ years, $21.6 \%$ in the age range $35-44$ years, and $8.6 \%$ in the age range 45 and over. In terms of education level, $8.6 \%$ of respondents had less than a high school diploma, $35.6 \%$ had a high school diploma, $31.5 \%$ had an undergraduate degree, and $24.2 \%$ had a graduate degree. In terms of occupation, the results showed that $38.3 \%$ were students, $48 \%$ were employed, $3.4 \%$ were retired, and $9.9 \%$ had other work.

The questions regarding how respondents access Twitter and how often they read and post tweets enabled us to provide a description of Twitter usage among the community. The means by which most of the respondents $(89.6 \%)$ access Twitter was smart phone, with an equal proportion accessing the service using laptops and personal computers $(5.2 \%)$.

Owing to the fact that not all Twitter users are active users, we posed two further questions in the questionnaire to target distinct Twitter activities and investigate actual users. The results indicated that respondents read (mean score $=3.54, S D=1.21$ ) and post (mean score $=3.00, S D=1.29$ ) tweets frequently. Table 1 presents descriptive statistics regarding Twitter users.

\begin{tabular}{|c|c|c|c|c|}
\hline \multicolumn{5}{|c|}{ Table 1: Statistics descriptive data of Twitter users } \\
\hline Demographics & & $\begin{array}{c}\text { Likert } \\
\text { scale }\end{array}$ & Frequency & Percentage \\
\hline Gender & $\begin{array}{l}\text { Male } \\
\text { Female }\end{array}$ & $\begin{array}{l}1 \\
2\end{array}$ & $\begin{array}{l}227 \\
236\end{array}$ & $\begin{array}{l}49 \\
51\end{array}$ \\
\hline Age & $\begin{array}{l}\text { Under } 18 \\
18-24 \text { years } \\
25-34 \text { years } \\
35-44 \text { years } \\
45 \text { and over } \\
\end{array}$ & $\begin{array}{l}1 \\
2 \\
3 \\
4 \\
5\end{array}$ & $\begin{array}{l}0 \\
291 \\
32 \\
100 \\
40 \\
\end{array}$ & $\begin{array}{l}0 \\
62.9 \\
6.9 \\
21.6 \\
8.6 \\
\end{array}$ \\
\hline Level of education & $\begin{array}{l}\text { Less than high school } \\
\text { High school diploma } \\
\text { Undergraduate degree } \\
\text { Graduate degree }\end{array}$ & $\begin{array}{l}1 \\
2 \\
3 \\
4\end{array}$ & $\begin{array}{l}40 \\
165 \\
146 \\
112\end{array}$ & $\begin{array}{l}8.6 \\
35.6 \\
31.5 \\
24.2 \\
\end{array}$ \\
\hline Occupation & $\begin{array}{l}\text { Student } \\
\text { Employed } \\
\text { Retired } \\
\text { Others } \\
\end{array}$ & $\begin{array}{l}1 \\
2 \\
3 \\
4 \\
\end{array}$ & $\begin{array}{l}187 \\
223 \\
16 \\
37 \\
\end{array}$ & $\begin{array}{l}38.4 \\
48.2 \\
3.5 \\
8.0 \\
\end{array}$ \\
\hline How do you access Twitter site? & $\begin{array}{l}\text { Smartphone } \\
\text { Laptop } \\
\text { Personal computer }\end{array}$ & $\begin{array}{l}1 \\
2 \\
3\end{array}$ & $\begin{array}{l}415 \\
24 \\
24\end{array}$ & $\begin{array}{l}89.2 \\
5.2 \\
5.2 \\
\end{array}$ \\
\hline $\begin{array}{l}\text { How often do you read tweets written } \\
\text { by others? }\end{array}$ & $\begin{array}{l}\text { Never } \\
\text { Rarely } \\
\text { Sometimes } \\
\text { Often } \\
\text { Very often } \\
\end{array}$ & $\begin{array}{l}1 \\
2 \\
3 \\
4 \\
5\end{array}$ & $\begin{array}{l}0 \\
123 \\
124 \\
56 \\
160 \\
\end{array}$ & $\begin{array}{l}0 \\
26.6 \\
26.8 \\
12.1 \\
34.6 \\
\end{array}$ \\
\hline $\begin{array}{l}\text { How often do you post tweets or re- } \\
\text { tweet? }\end{array}$ & $\begin{array}{l}\text { Never } \\
\text { Rarely } \\
\text { Sometimes } \\
\text { Often } \\
\text { Very often } \\
\end{array}$ & $\begin{array}{l}1 \\
2 \\
3 \\
4 \\
5 \\
\end{array}$ & $\begin{array}{l}57 \\
124 \\
130 \\
62 \\
90\end{array}$ & $\begin{array}{l}12.3 \\
26.8 \\
28.1 \\
13.4 \\
19.4 \\
\end{array}$ \\
\hline
\end{tabular}




\section{Instrument Validation}

Although the scales were adopted from various previous studies on SNS and technology adoption, to our knowledge, there is little research that combines DOI, U\&G, and trust. Thus, we used an exploratory factor analysis to test the validity of each construct using the principal axis factoring analysis extraction in SPSS. The initial total number of constructs in the study was 19, classified into three dimensions: perceived Twitter constructs, perceived needs, and perceived trust constructs. The results yielded 18 factors with a low and high internal reliability. In fact, the results showed that the constructs of information seeking and information sharing are highly correlated, which means that the respondents in the survey make no fine distinction between these motivations. To avoid multicollinearity in the subsequent analyses, we combined these two motivations into a construct called "information need." Table 2 shows the factor correlation for all predictors of Twitter usage.

\begin{tabular}{|c|c|c|c|c|c|c|c|c|c|c|c|c|c|c|c|c|c|c|}
\hline \multicolumn{19}{|c|}{ Table 2: Cross-correlations for all constructs } \\
\hline Factor & TTC & TIN & INF & PT & PP & $\mathrm{ESC}$ & INU & $\mathrm{COM}$ & VIS & ENT & RA & $\mathrm{RD}$ & PRA & INN & TRI & TTP & REL & EOU \\
\hline \multicolumn{19}{|l|}{ TTC } \\
\hline TIN & .530 & & & & & & & & & & & & & & & & & \\
\hline INF & .322 & .289 & & & & & & & & & & & & & & & & \\
\hline PT & .310 & .301 & .324 & & & & & & & & & & & & & & & \\
\hline PP & .250 & .382 & .359 & .389 & & & & & & & & & & & & & & \\
\hline ESC & .511 & .448 & .195 & .352 & .323 & & & & & & & & & & & & & \\
\hline INU & .341 & .244 & .494 & .269 & .278 & .192 & & & & & & & & & & & & \\
\hline $\mathrm{COM}$ & .343 & .332 & .448 & .347 & .269 & .277 & .251 & & & & & & & & & & & \\
\hline VIS & .194 & .236 & .419 & .225 & .334 & .097 & .278 & .248 & & & & & & & & & & \\
\hline ENT & .356 & .438 & .602 & .501 & .472 & .346 & .345 & .413 & .326 & & & & & & & & & \\
\hline RA & .288 & .173 & .523 & .223 & .399 & .281 & .324 & .448 & .142 & .421 & & & & & & & & \\
\hline $\mathrm{RD}$ & .056 & .138 & .354 & .128 & .247 & .071 & .190 & .264 & .353 & .312 & .274 & & & & & & & \\
\hline PRA & .423 & .394 & .247 & .273 & .299 & .500 & .323 & .420 & .132 & .277 & .318 & .001 & & & & & & \\
\hline INN & .159 & .202 & .367 & .382 & .428 & .187 & .234 & .333 & .182 & .369 & .311 & .319 & .183 & & & & & \\
\hline TRI & .222 & .222 & .217 & .254 & .359 & .181 & .232 & .258 & .319 & .251 & .231 & .270 & .197 & .285 & & & & \\
\hline ТTP & .566 & .574 & .404 & .276 & .280 & .457 & .363 & .428 & .242 & .431 & .264 & .193 & .417 & .287 & .255 & & & \\
\hline REL & .332 & .270 & .339 & .491 & .319 & .331 & .274 & .304 & .213 & .515 & .292 & .163 & .370 & .296 & .241 & .345 & & \\
\hline EOU & .206 & .257 & .427 & .264 & .255 & .179 & .234 & .430 & .360 & .371 & .274 & .316 & .299 & .288 & .230 & .475 & .288 & \\
\hline \multicolumn{19}{|c|}{$\begin{array}{l}\text { Note: } \mathrm{TTC}=\text { Trust in Twitter Community; TIN=Trust in Internet; INF= Information Need; PT=Pass Time; } \\
\text { PP=Perceived Popularity; ESC=Escape; INU=Interpersonal Utility; COM=Compatibility; VIS=Visibility; } \\
\text { INT=Entertainment; RA=Relative Advantage; RD=Result Demonstrability; PRA=Professional Advance- } \\
\text { ment; INN=Personal Innovativeness; TRI=Trialability; TTP=Trust in Twitter Provider; REL=Relaxation; } \\
\text { EOU=Ease of Use. }\end{array}$} \\
\hline
\end{tabular}

Because of a low internal reliability in a number of constructs, 19 items were removed to increase the internal reliabilities to more than .45. Following the removal of these 19 , the item statistics 
were re-assessed for the remaining 48 items. To ensure internal validity of the different constructs, Cronbach's alpha was computed. Cronbach's alpha is used to measure how well a set of variables used in an instrument can determine a one-dimensional construct through coefficient reliability. Table 3 shows an acceptable level of internal validity.

Table 3: Descriptive statistics and reliability analysis for Twitter adoption

\begin{tabular}{|c|c|c|c|c|c|}
\hline Variable & Items & Factor loadings & Mean score & SD & Cronbach's alpha \\
\hline Usage $^{\mathrm{a}}$ & $\begin{array}{l}1 \\
2\end{array}$ & $\begin{array}{l}.884 \\
.841\end{array}$ & 3.27 & 1.13 & .77 \\
\hline Personal innovativeness & $\begin{array}{l}1 \\
2\end{array}$ & $\begin{array}{l}.819 \\
.520\end{array}$ & 3.76 & .83 & .69 \\
\hline Perceived popularity & $\begin{array}{l}1 \\
2 \\
3 \\
\end{array}$ & $\begin{array}{l}.935 \\
.736 \\
.722 \\
\end{array}$ & 3.52 & 1.01 & .84 \\
\hline Relative advantage & $\begin{array}{l}1 \\
2 \\
3\end{array}$ & $\begin{array}{l}.788 \\
.570 \\
.510\end{array}$ & 3.60 & .78 & .73 \\
\hline Ease of use & $\begin{array}{l}1 \\
2\end{array}$ & $\begin{array}{l}.703 \\
.648 \\
\end{array}$ & 4.23 & .62 & .96 \\
\hline Compatibility & $\begin{array}{l}1 \\
2\end{array}$ & $\begin{array}{l}.946 \\
.744\end{array}$ & 3.48 & .95 & .83 \\
\hline Visibility & $\begin{array}{l}1 \\
2 \\
3\end{array}$ & $\begin{array}{l}.725 \\
.667 \\
.518\end{array}$ & 4.15 & .62 & .67 \\
\hline Result demonstrability & $\begin{array}{l}1 \\
2 \\
\end{array}$ & $\begin{array}{l}.789 \\
.669 \\
\end{array}$ & 3.98 & .74 & .75 \\
\hline Trialability & $\begin{array}{l}1 \\
2\end{array}$ & $\begin{array}{l}.749 \\
.620 \\
\end{array}$ & 3.95 & .74 & .77 \\
\hline Entertainment & $\begin{array}{l}1 \\
2 \\
3\end{array}$ & $\begin{array}{l}.909 \\
.733 \\
.568\end{array}$ & 3.81 & .83 & .83 \\
\hline Passing time & $\begin{array}{l}1 \\
2 \\
3\end{array}$ & $\begin{array}{l}.776 \\
.741 \\
.666\end{array}$ & 3.57 & .96 & .83 \\
\hline Escape & $\begin{array}{l}1 \\
2 \\
\end{array}$ & $\begin{array}{l}.877 \\
.829 \\
\end{array}$ & 2.56 & 1.17 & .86 \\
\hline Relaxation & $\begin{array}{l}1 \\
2\end{array}$ & $\begin{array}{l}.826 \\
.545 \\
\end{array}$ & 3.35 & .94 & .72 \\
\hline Information need & $\begin{array}{l}1 \\
2 \\
3 \\
4\end{array}$ & $\begin{array}{l}.827 \\
.774 \\
.695 \\
.506\end{array}$ & 4.03 & .70 & .81 \\
\hline Interpersonal utility & $\begin{array}{l}1 \\
2 \\
\end{array}$ & $\begin{array}{l}.920 \\
.804 \\
\end{array}$ & 3.82 & .87 & .81 \\
\hline Professional advancement & $\begin{array}{l}1 \\
2 \\
3\end{array}$ & $\begin{array}{l}.740 \\
.625 \\
.577\end{array}$ & 3.14 & .93 & .74 \\
\hline Trust in Twitter provider & $\begin{array}{l}1 \\
2 \\
3\end{array}$ & $\begin{array}{l}.880 \\
.564 \\
.479\end{array}$ & 3.52 & .84 & .82 \\
\hline Trust in Twitter community & $\begin{array}{l}1 \\
2 \\
3 \\
4\end{array}$ & $\begin{array}{l}.773 \\
.717 \\
.608 \\
.572 \\
\end{array}$ & 3.39 & .79 & .84 \\
\hline
\end{tabular}


Table 3: Descriptive statistics and reliability analysis for Twitter adoption

\begin{tabular}{|l|c|c|c|c|c|}
\hline Variable & Items & Factor loadings & Mean score & SD & Cronbach's alpha \\
\hline Trust in internet & 1 & .935 & 3.28 & .99 & .87 \\
& 2 & .835 & & & \\
& 3 & .776 & & & \\
\hline
\end{tabular}

Note: Five-point Likert-type scale, $1=$ strongly disagree and $5=$ strongly agree.

${ }^{a}$ Five-point Likert-type scale, $1=$ never and $5=$ very often.

\section{Determinants of Twitter Usage}

For this study, we selected and examined factors that influence Twitter usage using multiple regression analysis. Multiple regression analysis is used to examine the effect of a combination of two or more predictor variables on a criterion variable (Gall, Gall, \& Borg, 2007). The independent variables include three dimensions - Twitter characteristics, perceived needs, and trust characteristics - while the dependent variable is the use of Twitter.

The use of multiple regression analysis requires that data must meet certain conditions in order for analysis to be effective. In the hierarchical regression analysis, the histogram was bell shaped, which reflects the normal distribution of the data. Consistent with the condition of the linearity, the scatter plot of residuals confirmed the absence of outliers, and a clear curve between the predictors and the criterion variable. Lastly, the examination of collinearity was assessed by the variance inflation factor (VIF), the value of which should not exceed 9. The results of the VIF confirm that there was no collinearity issue among the independent variables.

Table 4 presents the results of the hierarchical regression model that examined how Twitter characteristics, perceived needs, and trust constructs could predict the usage of Twitter among the Kuwaiti community. In Model 1, the hierarchical regression test was carried out to evaluate the independent variables of the DOI model, namely personal innovativeness, relative advantage, ease of use, compatibility, visibility, result demonstrability, trialability, and perceived popularity. The constructs of the DOI model explained $13.4 \%$ of the variance in the use of Twitter. As a result of the analysis, we found that perceived relative advantage $(\beta=.208, p<0.001)$, perceived innovativeness $(\beta=.121, p<0.05)$, and perceived trialability $(\beta=.117, p<0.05)$ significantly affect the use of Twitter. However, the value of $\beta$, which is the standardized regression coefficient, confirmed that perceived relative advantage has a relatively stronger effect on the use of Twitter than perceived trialability and personal innovativeness.

Model 2 includes all of the aforementioned variables, with the addition of perceived needs (entertainment, passing time, escape, relaxation, information sharing, information seeking, interpersonal utility, and professional advancement). The $\mathrm{R}$ square $\left(\mathrm{R}^{2}\right)$ is 0.197 ; this indicates that $19.7 \%$ of the use of Twitter is explained by the constructs of DOI (13.4\%) and perceived needs $(6.3 \%)$. The results show the effect of perceived relative advantage $(\beta=.166, p<0.01)$ from the constructs of DOI and the effect of need for information $(\beta=.169, p<0.01)$, passing time $(\beta=.147, p<0.05)$, and interpersonal utility $(\beta=.105, p<0.05)$ from the U\&G. The value of $\beta$, which is the standardized regression coefficient, confirmed that perceived relative advantage and the need for information have a relatively stronger effect on the use of Twitter than the need to pass the time and for interpersonal utility.

Model 3 includes the constructs of DOI theory and U\&G theory, with the addition of trust characteristics (trust in the Twitter community, in the Twitter provider, and in the internet). All constructs of the three dimensions explained $20 \%$ of the variance in the use of Twitter; this indicates that trust explained less than $0.05 \%$ of the usage. The results of the model showed the ongoing effect of the four constructs recognized in Model 2 with the same order of effect. Thus, H5 ("The 
rate of Twitter usage is significantly predicted by the trust in the Twitter provider, trust in other members, and structural assurance") is rejected.

\begin{tabular}{|c|c|c|c|c|c|c|}
\hline \multicolumn{7}{|c|}{ Table 4: Multiple regression analysis of Twitter usage } \\
\hline \multirow[t]{2}{*}{ Variables } & \multicolumn{2}{|c|}{ Model 1} & \multicolumn{2}{|c|}{ Model 2} & \multicolumn{2}{|c|}{ Model 3} \\
\hline & $b$ & $\boldsymbol{\beta}$ & $b$ & $\beta$ & $B$ & $\beta$ \\
\hline Personal innovativeness & $\begin{array}{l}.121^{*} \\
(.069)\end{array}$ & 164 & $\begin{array}{l}.049 \\
(.071)\end{array}$ & .066 & $\begin{array}{l}.054 \\
(.071)\end{array}$ & .073 \\
\hline Perceived popularity & $\begin{array}{l}-.033 \\
(.058)\end{array}$ & -.036 & $\begin{array}{l}-.072 \\
(.060)\end{array}$ & -.080 & $\begin{array}{l}-.079 \\
(.060)\end{array}$ & -.088 \\
\hline Relative advantage & $\begin{array}{l}.208^{* *} \\
(.079)\end{array}$ & .300 & $\begin{array}{l}.166^{* *} \\
(.081)\end{array}$ & .239 & $\begin{array}{l}.174^{* *} \\
(.082)\end{array}$ & .250 \\
\hline Ease of use & $\begin{array}{l}.012 \\
(.099)\end{array}$ & .022 & $\begin{array}{l}-.003 \\
(.097)\end{array}$ & -.005 & $\begin{array}{l}-.008 \\
(.098)\end{array}$ & -.014 \\
\hline Compatibility & $\begin{array}{l}-.017 \\
(.064)\end{array}$ & -.020 & $\begin{array}{l}-.066 \\
(.064)\end{array}$ & -.078 & $\begin{array}{l}-.072 \\
(.065)\end{array}$ & -.086 \\
\hline Result demonstrability & $\begin{array}{l}.073 \\
(.080)\end{array}$ & .111 & $\begin{array}{l}.055 \\
(.078)\end{array}$ & .083 & $\begin{array}{l}.062 \\
(.079)\end{array}$ & .094 \\
\hline Visibility & $\begin{array}{l}.019 \\
(.098)\end{array}$ & .039 & $\begin{array}{l}-.028 \\
(.097)\end{array}$ & -.056 & $\begin{array}{l}-.035 \\
(.098)\end{array}$ & -.069 \\
\hline Trialability & $\begin{array}{l}.117^{*} \\
(.082)\end{array}$ & .180 & $\begin{array}{l}.059 \\
(.082)\end{array}$ & .090 & $\begin{array}{l}.057 \\
(.082)\end{array}$ & .088 \\
\hline Entertainment & & & $\begin{array}{l}.038 \\
(.084)\end{array}$ & .051 & $\begin{array}{l}.032 \\
(.084)\end{array}$ & .044 \\
\hline Pass time & & & $\begin{array}{l}.147^{*} \\
(.068)\end{array}$ & .172 & $\begin{array}{l}.143^{*} \\
(.068)\end{array}$ & .168 \\
\hline Escape & & & $\begin{array}{l}-.005 \\
(.051)\end{array}$ & -.005 & $\begin{array}{l}-.014 \\
(.054)\end{array}$ & -.014 \\
\hline Relaxation & & & $\begin{array}{l}.010 \\
(.067)\end{array}$ & .012 & $\begin{array}{l}.007 \\
(.067)\end{array}$ & .008 \\
\hline Information & & & $\begin{array}{l}.169^{* *} \\
(.095)\end{array}$ & .271 & $\begin{array}{l}.170^{* *} \\
(.097)\end{array}$ & .271 \\
\hline Interpersonal utility & & & $\begin{array}{l}.105^{*} \\
(.063) \\
\end{array}$ & .137 & $\begin{array}{l}.109^{*} \\
(.064) \\
\end{array}$ & .142 \\
\hline Professional advancement & & & $\begin{array}{l}-.040 \\
(.067)\end{array}$ & -.049 & $\begin{array}{l}-.061 \\
(.070)\end{array}$ & -.074 \\
\hline Trust in Twitter provider & & & & & $\begin{array}{l}-.030 \\
(.086)\end{array}$ & -.041 \\
\hline Trust in Twitter community & & & & & $\begin{array}{l}.031 \\
(.089)\end{array}$ & .044 \\
\hline Trust in internet & & & & & $\begin{array}{l}.062 \\
(.064)\end{array}$ & .070 \\
\hline Intercept & & & & & & \\
\hline F value & & & & & & \\
\hline $\mathrm{R}^{2}$ & & & & & & \\
\hline Adj. $R^{2}$ & & & & & & \\
\hline $\begin{array}{l}\text { Notes Standard errors are sho } \\
* \mathrm{p}<.05 \\
* * \mathrm{p}<.0 .01 \\
* * * \mathrm{p}<.001\end{array}$ & enthese & & & & & \\
\hline
\end{tabular}




\section{Discussion and Conclusion}

This study represents an important contribution to theory in that it integrates three theoretical perspectives to identify factors that might influence the use of Twitter among individuals in Kuwait. The underlying framework used in this research is the integrated model of DOI, U\&G, and trust theory.

\section{Twitter Usage}

It seems that the improved interfaces on smart phones and other similar devices have played an essential role in increasing the number of users. In fact, $89 \%$ of the respondents access the Twitter service via smart phones, while $10 \%$ access Twitter via laptops or personal computers. However, we considered that those who have Twitter accounts may not be active users, so we explored this aspect by setting further questions regarding the reading and posting of tweets. Although the general results suggest that the levels of these activities are moderate, the extra details indicate that the respondents are more active in reading than in posting tweets. The fact that our respondents post tweets rarely and read tweets regularly suggests that the participants are information seekers in the context of Twitter technology (Java et al., 2007).

\section{Hypotheses Test Results}

In terms of gaining a holistic understanding of Twitter usage by integrating three theoretical perspectives - DOI, U\&G, and trust theory- the findings show that the three models combined explained variance for the rate of the Twitter usage to $20 \%$. DOI and U\&G significantly contributed to the explained variance ( $13.4 \%$ and $6.2 \%$ respectively), while trust theory did not contribute significantly to the variance $(0.3 \%)$. Further details of the prediction are discussed in the following sections, based on the constructs of each theoretical perspective.

\section{Diffusion of Innovation}

For the DOI construct, the results of Model 1 indicate the significant influence of relative advantage, personal innovativeness, and trialability on Twitter usage, whereas Models 2 and 3 merely show the highly significant effect of relative advantage on Twitter usage. Hence, the only consistent and highly significant construct from the DOI perspective is the perceived relative advantage of Twitter technology. Undoubtedly, perceived relative advantage is the crucially influ-

ential ingredient of Twitter usage because Twitter technology enables users to obtain several benefits, including daily chat, conversations, sharing information and knowledge, and reporting news (Java et al., 2007). The results are consistent with Ribiere et al.'s (2010) findings in the context of the usefulness of SNSs in three countries: USA, Bahrain, and Thailand. Thus, the greater the relative advantage that a person considers Twitter to be, the more likely they are to become an adopter of Twitter. Despite the significant contribution of personal innovativeness and perceived trialability in Model 1, the contributions of these constructs were insignificantly effective when U\&G was applied in Models 2 and 3. The effectiveness of the Twitter service becomes apparent when high numbers of individuals use the service, so these findings minimized the effect of personal innovativeness after U\&G constructs were applied. Moreover, it seems that Twitter has significantly satisfied users' needs, so individuals are willing to adopt it even without experiments. Some researchers in the DOI literature found that perceived relative advantage influences technology usage (Chang et al., 2006; Zhu \& He, 2002) and Twitter usage (Coursaris et al., 2013). The possible reasons behind the significant effectiveness of relative advantage on Twitter usage will be interpreted further by applying the perspective of U\&G. Owing to possible measurement errors related to low loading factors of several items, the small number of items for some factors, and small sample sizes, several factors were found to be insignificant in effecting Twitter adoption, including perceived popularity, ease of use, compatibility, visibility, and result demonstra- 
bility. These measurement errors might also affect the contribution to the variance in rate adoption, which was indicated by Rogers (2003) to be between $49 \%$ and $87 \%$.

\section{Uses and Gratifications}

As briefly discussed earlier, the findings indicated that perceived needs in relation to the Twitter service play an efficient role in predicting Twitter usage. Although the contribution of the constructs of U\&G was less than the contribution of the constructs of DOI in the explained variance, U\&G significantly affected Twitter usage in relation to three constructs, namely the need for information, the need to pass time, and the need for interpersonal utility. However, results showed that the need for information is the most significant predictor of Twitter usage. In our research, the two activities of information seeking and information sharing were combined in a factor called "information need." The combination of these two activities might empower its effect in predicting the use of Twitter. Based on this finding, it would appear that users are utilizing Twitter more for information-sharing and -seeking purposes than to pass time or for interpersonal utility purposes in the Arab context. Al-Jabri et al. (2015) identified the role of Twitter in expressing opinions and discussing different issues, even in countries in which freedom is restricted. Ribiere et al. (2010) found that acquiring knowledge and information from others is the pivot for using SNSs in the culture of the USA, Bahrain, and Thailand. Since passing time and interpersonal utility appeared to be less salient needs, it seems that Twitter is becoming increasingly recognized, at least as an information tool (Johnson \& Yang, 2009; Java et al., 2007), for passing time as well as for interpersonal utility, instead of face-to-face social contacts.

The findings indicate that Twitter is more successful in releasing real-time information than other media. Given the possibility of a shortage and weakness of information sources nationally, organizations should ensure that Twitter is being utilized for information. Based on the results of U\&G, the perceived relative advantage of Twitter is explained by the need for Twitter to function as a tool for information, passing time, and interpersonal utility rather than as a tool for relaxation, entertainment, professional advancement, or escape. The findings can be seen as consistent with Papacharissi and Rubin's (2000) findings, and partially consistent with Coursaris et al.'s (2013) findings. The focus of this study was only one particular social media application - Twitter which was created for the purpose of sharing real-time information; thus, it is not a venue where users can relax, entertain, or escape. These findings are inconsistent with the results on the motivation of different social media applications in different cultures (Kurtulus \& Ozkan, 2015). Furthermore, rejecting the effect of relaxation, entertainment, professional advancement, and escape might be influenced by a variety of moderators and mediators, such as social factors, user characteristics, platform attributes, and user attributes. Therefore, future studies need to reexamine comparatively the factors relating to different SNSs and examine the effect of the mediators and moderators on the relationships of the rejected factors to Twitter adoption in the communities of developing countries.

\section{Trust Theory}

The literature of trust has discussed trust based on multiple dimensions (Chai \& Kim, 2010; Gefen et al., 2003; McKnight et al., 2002). The current research focused on three trust objects in the context of Twitter: trust in the Twitter community, trust in the Twitter provider, and trust in the internet. Based on empirical support for the influence of trust in the level of SNS and Twitter usage, we hypothesized on the significance of trust objects as a considerable antecedent of Twitter usage. Unexpectedly, the results of Model 3 did not statistically support a significant relationship between trust objects and Twitter usage. Investigations into trust in relation to Twitter usage in the Kuwaiti community are, to our knowledge, extremely limited. The findings of this research may be consistent with other future studies conducted in Kuwaiti culture, but are inconsistent with the findings for other cultures (e.g. USA, Australia, and China). One explanation for this 
phenomenon might be that participants are not interested in trust owing to the general usage of Twitter in our study. It is common for some Twitter accounts are real and others fake, and it seems acceptable for both of these to be followed for general usage by users. However, investigating Twitter usage in a particular local organization for specific purposes (e.g. information and knowledge sharing) can produce different results. For example, Park, Choi, Kim, and Rho (2015) identified the formation of citizens' trust toward SNSs provided by government agencies. The insignificant effect of trust objects could also be influenced by the availability of other means or channels in which members might have more confidence in connecting with other individuals. Twitter providers should give trustworthiness more prominence in order for it to become a main communication channel between business representatives, government representatives, and individuals.

\section{Implications}

The findings of the current study have some important implications for both theory and practice. The results also contribute to the transdisciplinary perspective of informing sciences because they highlight the importance of human-related issues and technology-related issues in explaining Twitter usage and acceptance as an informing channel. This study extends the previous literature by combining the relative strengths of three theoretical perspectives - DOI, U\&G, and trust theo-

ry - to offer a more comprehensive model for understanding technology adoption in the culture of the Arab world. The methods and resultant findings of this study expand the applications of DOI, U\&G, and trust theory in the study of new media such as SNSs in the literature of the Middle East in particular. Twitter's strengths and weakness were identified based on three popular theoretical perspectives in an area that still suffers from limited use of theory in its literature. Furthermore, the applications of DOI and U\&G in this study provide complementary insights into material characteristics and user-related characteristics. For example, as a material characteristic, the relative advantage of Twitter usage was supported and specified by the user-related characteristics, such as the need for information, need to pass time, and need for interpersonal utility.

Further implications revolve around Twitter's relative advantage and the strength of information motivation. Clearly, Twitter is becoming one of the most important channels for information flow. Therefore, decision makers in governments, organizations, institutions, and firms should make efforts to employ Twitter as an official channel for rich information sharing, information seeking, and information and knowledge management that is more responsive to users' needs. This study also provides details of Twitter's strengths and weakness, which could serve as a guideline to enable Twitter providers to increase and promote the use of the technology. In addition, identifying challenges and training opportunities associated with the use of Twitter in institutions is fundamental for ongoing and appropriate usage and higher levels of credibility. Lastly, smart phones were identified as an important means of access to Twitter. Therefore, in order to avoid failures in the acceptance and use of current and future information and communication systems, such as e-learning, e-government, and e-business, decision makers should modify these systems so that they have effective interfaces for access through smart phones.

\section{Limitations and Future Research}

Although this research has reported significant findings in the context of SNSs, several limitations were identified and need to be discussed for further analysis in future studies. First, because this study applied the quantitative approach to analyze the data, a further study that uses mixedmeasure approaches in analyzing data needs to be carried out. In the current study, we investigated the motivations for Twitter usage by using needs that were previously identified in other cultures. Future studies need to use qualitative approaches to assist in identifying latent variables that 
might be specific to the societies of the Arab world, and also capture some motivations that are not considered in other studies.

Moreover, this study represents an attempt to investigate and predict the general usage of Twitter throughout Kuwaiti society. Future research should attempt to analyze Twitter usage in particular contexts to obtain a more accurate and dynamic understanding of innovation characteristics, motivations, and trust. Although this study provides clear explanations for some predictors of Twitter usage, it does not provide insights into further motivations that might be affected by trust theory (e.g. decision making and problem solving).

This research found that several factors were significant and others were insignificant in predicting Twitter adoption, but the research did not examine the effect of user characteristics as moderators or mediators on the results. Future research should focus on the effect of users' characteristics in predicting Twitter usage in the Arab world.

In this study, the total number of usable responses was 463 out of 645 questionnaires completed online. The majority of the respondents were between 18 and 24 years old, and nearly half of the total respondents (48\%) were employees. Furthermore, this study adopted an online questionnaire filled out by the followers of popular Twitter accounts in Kuwait. These constraints might lead to some restrictions in generalizing the findings of the study to all Twitter users in Kuwait. Future research should expand the scope of research to all Twitter users in Kuwait, in order to better understand the role of trust, attributes of innovation, and motivations for Twitter adoption in Kuwaiti society as a whole.

\section{Conclusion}

This study was motivated by the limited research base on social media in Middle East, specifically in Kuwait. Despite the diffusion of expensive technologies through most organizations in $\mathrm{Ku}-$ wait, official statistics have recorded extremely high numbers of social media users - Twitter in particular - compared with other technologies. Thus, this study was conducted not only to present descriptive statistics but also to investigate and understand the factors that influence the use of Twitter in Kuwait. Three well-known theoretical perspectives were applied in order to conduct the investigation and aid comprehension: DOI theory, U\&G theory, and trust theory.

This study allowed us to identify four factors that are influential on the general usage of Twitter (perceived relative advantage from DOI, and the need for information, the need to pass time, and the need for interpersonal utility from $U \& G)$. Although trust theory has been found to be meaningful in predicting social media usage in previous research, our study yielded unexpected results, with none of the trust constructs being influential. The surprising conclusions regarding the influence of trust theory on social and organizational usage suggest that this would be an interesting topic of discussion in future research.

Perceived relative advantage and the need for information are clearly the most important predictors for Twitter usage not only in Kuwait but also in the Arab world. Despite the variety of utilities that are related to Twitter usage, our study strongly identified the role of information motivation in predicting the use of Twitter as a new and useful channel of information flow.

\section{References}

Abdelhay, N. (2012). The Arab uprising 2011: New media in the hands of new generation in North Africa. Aslib Proceedings: New Information Perspectives, 64, 529-539.

Agarwal, R., \& Prasad, J. (1998). A conceptual and operational definition of innovativeness in the domain of information technology. Information System Research, 9, 204-215. 
Agrifoglio, R., Black, S., Metallo, C., \& Ferrara, M. (2012). Extrinsic versus intrinsic motivation in continued twitter usage. The Journal of Computer Information Systems, 53, 33-41.

Aladwani, A. (2015). Facilitators, characteristics, and impacts of Twitter use: Theoretical analysis and empirical illustration. International Journal of Information Management, 35, 15-25.

Al-Jabri, I., Sohail, S., \& Ndubisi, N. (2015). Understanding the usage of global social networking sites by Arabs through the lens of uses and gratifications theory. Journal of Service Management, 26, 662-680.

Awad, N., \& Ragowsky, A. (2008). Establishing trust in electronic commerce through online word of mouth: An examination across genders. Journal of Management Information Systems, 24(4), 101-121.

Barnes, S., \& Bohringer, M. (2011). Modeling use continuance behavior in microblogging services: The case of Twitter. The Journal of Computer Information Systems, 51, 1-10.

Blumler, J., \& Katz, E. (1974). The uses and mass communications: Current perspectives on gratifications research. Beverly Hills, CA: Sage Publications.

Chai, S., \& Kim, M. (2010). What makes bloggers share knowledge? An investigation on the role of trust. International Journal of Information Management, 30, 408-415.

Chang, B., Lee, S., \& Kim, B. (2006). Exploring factors affecting the adoption and continuance of online games among college students in South Korea. New Media \& Society, 8, 295-319.

Chopra, K., \& Wallace, W. (2003). Trust in electronic environments. Proceedings of the $36^{\text {th }}$ Hawaii International Conference on System Sciences. Retrieved from https://www.computer.org/csdl/proceedings/hicss/2003/1874/09/187490331a.pdf

Cohen, E. (2009). A philosophy of informing science. Informing Science: The International Journal of an Emerging Transdiscipline, 12, 1-15. Retrieved from http://www.inform.nu/Articles/Vol12/ISJv12p001-015Cohen399.pdf

Corritore, C., Kracher, L., \& Wiedenbeck, S. (2003). Online trust: Concepts, evolving themes, a model. International Journal of Human-Computer Studies, 58, 737-758.

Coursaris, C., Van Osch, W., Sung, J., \& Yun, Y. (2013). Disentangling Twitter's adoption and use (dis)continuance: A theoretical and empirical amalgamation of uses and gratifications and diffusion of innovations. AIS Transactions on Human-Computer Interaction, 5, 57-83.

Downes, S. (2005). Semantics networks and social networks. The Learning Organization, 12, 411-418.

Dubai School of Government (2013). Arab social media report. Retrieved from http://www.dsg.fohmics.net/en/asmr3/ASMRHome3.aspx

Dwyer, C., Hiltz, S., \& Passerini, K. (2007). Trust and privacy concern within social network sites: A comparison of Facebook and MySpace. Proceedings of the thirteenth Americas Conference on Information Systems (AMCIS). Retrieved from http://csis.pace.edu/ dwyer/research/DwyerAMCIS2007.pdf

Evangelopoulos, N., Magro, M., \& Sidorova, A. (2012). The dual micro/macro informing role of social networking sites: Can Twitter macro messages help predict stock prices? Informing Science: The International Journal of an Emerging Transdiscipline, 15, 247-268. Retrieved from http://www.inform.nu/Articles/Vol15/ISJv15p247-268Evangelopoulos0630.pdf

Fang, Y., \& Chiu, C. (2010). In justice we trust: Exploring knowledge-sharing continence intention in virtual communities of practice. Computers in Human Behavior, 26, 235-246.

Fulk, J. (1993). Social construction of communication technologies. Academy of Management Journal, 36, 921-950.

Gall, M. D., Gall, J. P., \& Borg, W. R. (2007). Educational research: An introduction. Boston, MA: Pearson Education.

Gefen, D., Karahanna, E., \& Straub, D. (2003). Trust and TAM in online shopping: An integrated model. MIS Quarterly, 27, 51-90. 
Grabner-Krauter, S. (2009). Web 2.0 social networks: The role of trust. Journal of Business Ethics, 90, 504-522.

Grabner-Krauter, S., \& Faullant, R. (2008). Consumer acceptance of Internet banking: The influence of Internet trust. International Journal of Bank Marketing, 26, 483-504.

Gunther, O., Krasnova, H., Riehle, D., \& Schonberg, V. (2009). Modeling micro-blogging adoption in the enterprise. Proceedings of the Fifteenth Americas Conference on Information Systems (AMCIS). Retrieved from http://dirkriehle.com/uploads/2009/04/microblogging-final-submission-18 04_2009.pdf

Hardin, G., Ryan, S., \& Prybutok, V. (2012). Social networking site continuance: The paradox of negative consequences and positive growth. Informing Science: The International Journal of an Emerging Transdiscipline, 15, 207-227. Retrieved from http://www.inform.nu/Articles/Vol15/ISJv15p207227Harden0628.pdf

Hargittai, E., \& Litt, E. (2011). The tweet smell of celebrity success: Explaining variation in Twitter adoption among diverse group of young adults. New Media \& Society, 13, 824-842.

Holton, A., Baek, K., Coddington, M., \& Yaschur, C. (2014). Seeking and sharing: Motivations for linking on Twitter. Communication Research Reports, 31, 33-40.

Honeycutt, C., \& Herring, S. (2009). Beyond microblogging: Conversation and collaboration via Twitter. Proceedings of the 42nd Hawaii International Conference on System Sciences (HICSS,), Big Island, HI, 1-10. Los Alamitos, CA: IEEE Press.

Java, A., Song, X., Finin, T., \& Tseng, B. (2007). Why we Twitter: Understanding microblogging usage and communities. Proceedings of the Joint 9th WEBKDD and 1st SNA-KDD Workshop. Retrieved from http://ebiquity.umbc.edu/_file_directory_/papers/369.pdf

Johnson, P., \& Yang, S. (2009). Uses and gratifications of Twitter: An examination of user motives and satisfaction of Twitter use. The Annual Meeting of the Association for Education in Journalism and Mass Communication. Retrieved from http://surface.syr.edu/cgi/viewcontent.cgi?article $=1057 \&$ context=thesis

Kang, M. H. (2002). Digital cable: Exploring factors associated with early adoption. Journal of Media Economics, 15(3), 193-207.

Kaplan, A. M., \& Haenlein, M. (2010). Users of the world, unite! The challenges and opportunities of social media. Business Horizons: Kelley School of Business, 53, 59-68.

Krasnova, H., Spiekermann, S., Koroleva, K., \& Hildebrand, T. (2010). Online social networks: Why we disclose? Journal of Information Technology, 25, 109-125.

Krishnamurthy, B., Gill, P., \& Arlitt, M. (2008). A few chirps about Twitter. Proceedings of the First Workshop on Online Social Networks. Retrieved from http://www2.research.att.com/ bala/papers/twit.pdf

Kurtulus, S., \& Ozkan, E. (2015). How do social media users in Turkey differ in terms of their use habits and preferences? International Journal of Business and Information, 10, 337-364.

Kwak, H., Lee, C., Park, H., \& Moon, S. (2010). What is Twitter, a social network or a news media? Proceedings of the 19th International Conference on World Wide Web (WWW'10), 591-600. New York, NY: ACM.

Lacka, E., \& Chong, A. (2015). Usability perspective on social media sites' adoption in the B2B context. Industrial Marketing Management, 54, 80-91.

Ladhani, N. (2012). Twitter: The people's network. Social Policy, 42, 65-66.

Lee, M., \& McLoughlin, C. (2010). Beyond distance and time constraints: Applying social networking tools and Web 2.0 approaches in distance learning. In G. Veletsianos (Ed.), Using emerging technologies in distance education (pp. 61-87). Edmonton: Athabasca University Press. 
Leung, L., \& Wei, R. (2000). More than just talk on the move: Uses and gratifications of the cellular phone. Journalism and Mass Communication Quarterly, 77, 308-320.

Li, J., \& Rao, H. (2010). Twitter as a rapid response news service: an exploration in the context of the 2008 China earthquake. The Electronic Journal on Information Systems in Developing Countries, 24(4), 122.

Lin, C. A. (1998). Exploring personal computer adoption dynamics. Journal of Broadcasting and Electronic Media, 42, 95-112.

Lin, H. (2011). An empirical investigation of mobile banking adoption: The effect of innovation attributes and knowledge-based trust. International Journal of Information Management, 31, 252-260.

Liu, Z., Liu, L., \& Li, H. (2012). Determinants of information retweeting in microblogging. Internet Research, 22, 443-466.

Loch, K., Straub, D., \& Kamel, S. (2003). Diffusing the internet in the Arab world: The role of the social norms and technological culturation. IEEE Transactions on engineering management, 5, 45-63.

Mayer, A. (2009). Online social networks in economics. Decision Support Systems, 47(3), 169-184.

Mayer, R., Davis, J., \& Schoorman, F. (1995). An integrative model of organizational trust. Academy of Management Review, 20, 709-734.

McKnight, D., Choudhury, V., \& Kacmar, C. (2002). Developing and validating trust measures for ecommerce: An integrative typology. Information System Research, 13, 334-359.

Midgley, D. F., \& Dowling, R. G. (1978). Innovativeness-concept and its measurement. Journal of Consumer Research, 4, 229-249.

Mills, A., Chen, R., Lee, J., \& Rao, H. R. (2009). Web 2.0 emergency applications: how useful can Twitter be for emergency response? Journal of Information Privacy \& Security, 5(3), 3-26.

Mocanu, D., Baronchelli, A., Perra, N., Gonçalves, B., Zhang, Q., \& Vespignani, A. (2013). The Twitter of Babel: Mapping World Languages through Microblogging Platforms. PLoS One, 8(4), 1-9.

Moore, G. C., \& Benbasat, I. (1991). Development of an instrument to measure the perceptions of adopting an information technology innovation. Information System Research, 2, 192-222.

Naaman, M., Becker, H., \& Gravano, L. (2011). Hip and trendy: Characterizing emerging trends on Twitter. Journal of the American Society for Information Science and Technology, 62, 902-918.

Papacharissi, Z. (2002). The self online: The utility of personal home pages. Journal of Broadcasting and Electronic Media, 46, 346-368.

Papacharissi, Z., \& Rubin, A. (2000). Predictors of Internet use. Journal of Broadcasting and Electronic Media, 44, 175-196.

Park, C., \& Kim, Y. (2013). Intensity of social network use by involvement: A study of young Chinese users. International Journal of Business and Management, 8(6), 22-33.

Park, M., Choi, H., Kim, S., \& Rho, J. (2015). Trust in government's social media service and citizen's patronage behavior. Telematics and Informatics, 32, 629-641.

Pere-Latre, F., Portilla, I., \& Blanco, C. (2010). Social networks, media and audiences: A literature review. Communication and Society, 24(1), 63-74.

Peterson, R. (2012). To tweet or not to tweet: Exploring the determinants of early adoption of Twitter by House members in the 111th Congress. The Social Science Journal, 49, 430-438.

Prybutok, G. (2013). YouTube: An effective Web 2.0 informing channel for health education to prevent STDs. Informing Science: The International Journal of an Emerging Transdiscipline, 16, 19-36. Retrieved from http://www.inform.nu/Articles/Vol16/ISJv16p019-036Prybutok0119.pdf

Ratnasingam, P. (2005). Trust in inter-organizational exchanges: A case study in business to business electronic commerce. Decision Support Systems, 39, 525-544. 
Ribiere, V., Haddad, M., \& Wiele, P. (2010). The impact of national cultural traits on the usage of Web 2.0 technologies. VIEN: The Journal of Information and Knowledge Management Systems, 40, 334-361.

Ridings, C., Gefen, D., \& Arinze, B. (2002). Some antecedents and effects of trust in virtual communities. The Journal of Strategic Information Systems, 11, 271-295.

Rogers, E. M. (2003). Diffusion of innovations (5th ed.). New York: Free Press.

Ross, C., Terras, M., Warwick, C., \& Welsh, A. (2011). Enabled backchannel: Conference Twitter use by digital humanists. Journal of Documentation, 67, 214-237.

Rousseau, D., Sitkin, S., Burt, R., \& Camerer, C. (1998). Not so different after all: A cross-discipline view of trust. Academy of Management Review, 23, 393-404.

Salem, F., \& Mourtada, R. (2012). Social media in the Arab world: Influencing societal and cultural change? Arab Social Media Report, 2(1), 1-29.

Sangwan, S. (2005). Virtual community success: A uses and gratifications perspective. The 38th Hawaii International Conference on System Sciences HICSS.

Schmitz, J., \& Fulk, J. (1991). Organizational colleagues, media richness, and electronic mail: A test of the social influence model of technology use. Communication Research, 18, 487-523.

Shirazi, F. (2013). Social media and the social movements in the Middle East and North Africa: A critical discourse analysis. Information Technology and People, 26, 28-49.

Sreenivasan, N., Lee, C., \& Goh, D. (2012). Tweeting the friendly skies: Investigating information exchange among Twitter users about airlines. Program, 46, 21-42.

Stafford, T. F., \& Stafford, M. R. (1998). Uses and gratifications of the World Wide Web: A preliminary study. Proceedings of the 1998 American Academy of Advertising Conference.

Stafford, T. F., Stafford, M. R., \& Schkade, L. L. (2004). Determining uses and gratifications for the internet. Decision Sciences, 35, 259-288.

Stanciu, A., Mihai, F., \& Aleca, O. (2012). Social networks as an alternative environment for education. Accounting and Management Information Systems, 11(1), 56-75.

Statistic Brain. (2014). Twitter statistics. Retrieved from www.statisticbrain.com/twitter-statistics

Straub, D., Loch, K., \& Hill, C. (2001). Transfer of information technology to the Arab world: A test of cultural influence modeling. Journal of Global Information Management, 9(4), 6-28.

Taddeo, M. (2010). Modeling trust in artificial agents, a first step toward the analysis of e-trust. Minds and Machines, 20, 243-257.

Tornatzky, L., \& Klien, K. (1982). Innovation characteristics and adoption-implementation: A meta analysis of findings. IEEE Transaction on Engineering Management, 29(1), 28-45.

Tufekci, Z. (2008). Can you see me now? Audience and disclosure regulation in online social network sites. Bulletin of Science, Technology, and Society, 28, 20-36.

Turel, O., \& Gefen, D. (2013). The dual role of trust in system use. Journal of Computer Information Systems, 54, 2-10.

Witkemper, C., Lim, C., \& Waldburger, A. (2012). Social media and sports marketing: Examining the motivations and constraints of Twitter users. Sport Marketing Quarterly, 2, 170-183.

Zhao, D., \& Rosson, D. (2009). How and why people Twitter: The role that microblogging plays in information communication at work. Proceedings of the ACM 2009 International Conference on Supporting Group Work.

Zhu, J., \& He, Z. (2002). Perceived characteristics, perceived needs, and perceived popularity: Adoption and use of the Internet in China. Communication Research, 29, 466-495. 


\section{Biographies}

Dr. Mohammad A. Alajmi is an assistant professor in the Department of Library and Information Science at the Public Authority for Applied education and Training in Kuwait. He received his Ph.D and Master of Sciences in Information Science from University of North Texas. His research focuses on the individual and organizational adoption and usage of ICTs, including digital libraries, database systems, and social networking technologies. He has published in the International Information \& Library Review. He has presented several international conference papers on these topics.

Dr. Awadh Alharbi is an assistant professor in the Department of Library and Information Science at The Public Authority for Applied Education and Training. He holds a Ph.D in Australia from Queensland University of Technology (QUT) where he specializes in library services. His MS is from UK at Northumbria University. Dr. Awadh published several studies on the subjects of academic library services and information Science. He has published in Library Hi Tech.

Dr. Husain F. Ghuloum is an assistant professor in the Department of Library and Information Sciences (DLIS) at the Public Authority for Applied and Education (PAAET) in the State of Kuwait for around three years. Dr. Ghuloum got his Masters of Information Science at Leeds Metropolitan University and his Ph.D in Information Systems at Salford University. Dr. Husian has published several studies on the subjects of libraries and information Science. He has published in Information Development and Journal of Librarianship and Information Science. 